\title{
Self-Plasticization of PVC via click reaction of a monooctyl phthalate derivative
}

\author{
Puyou Jia ${ }^{1}$, Rui Wang ${ }^{3}$, Lihong Hu${ }^{1,2}$, Meng Zhang ${ }^{1,2}$, Yonghong Zhou ${ }^{1 *}$ \\ ${ }^{1}$ Institute of Chemical Industry of Forest Products, Chinese Academy of Forestry (CAF); National Engineering Lab for \\ Biomass Chemical Utilization; Key Lab on Forest Chemical Engineering, State Forestry Administration; and Key Lab of \\ Biomass Energy and Materials, Jiangsu Province, 16 Suojin North Road, Nanjing 210042, P.R. China \\ ${ }^{2}$ Chinese Academy of Forest (CAF), Institute of New Technology of Forestry, Beijing 100091, P. R. China \\ ${ }^{3}$ Nanjing Forestry University, College of Materials Science and Engineering, Nanjing 210037, China \\ "Corresponding author: e-mail: yhzhou777@sina.com
}

\begin{abstract}
Modified PVC (M-PVC) material with suppressed migration and low glass transition temperature was prepared via click reaction of a monooctyl phthalate derivative. Chemical structure and composition of M-PVC were characterized by FT-IR, 1H NMR and element analysis. Thermal stability, glass transition temperature and migration stability of M-PVC were studied with TGA, DSC and migration tests, respectively. The study showed that M-PVC exhibited poor thermal stability, and low glass transition temperature of $66.0^{\circ} \mathrm{C}$. No migration was found in distilled water, $10 \%(\mathrm{v} / \mathrm{v})$ ethanol, $30 \%(\mathrm{w} / \mathrm{v})$ acetic acid and petroleum ether. The PVC material is expected to preparing PVC products in the areas with high migration resistance requirement.
\end{abstract}

Keywords: poly(vinyl chloride), plasticization, migration, TGA.

\section{INTRODUCTION}

Plasticizer is an important plastic additive, which has been used to improve the processing property, flexibility and tensile property of plastic, resin and elastomer. As the commonly used plasticizer, dioctyl phthalate (DOP) has been widely used in child toys, food packaging materials, blood transfusion tube, wire and cable materials due to low price and high plasticizing effect ${ }^{1-4}$. However, the leaching of DOP from PVC materials cannot be avoided with the extent of time, which will change the properties of PVC products and decrease their service life. In addition, it will be toxic effect on human body once DOP enters human body via mouth, respiratory tract, intravenous infusion or skin absorption ${ }^{5-7}$. DOP has been prohibited from being used in children toys, food packing materials and medical apparatus and instruments in the United States, Japan, Korean and European Union ${ }^{\mathbf{8}, \boldsymbol{9}}$. In China, the production of plasticizer has reached 3 million tons a year, $80 \%$ of these plasticizers is phthalates ${ }^{\mathbf{1 0}}$. In order to avoid plasticizer migration, many new types of plasticizers has been synthesized and studied such as epoxidized soybean oil ${ }^{11}$, palm oil-based polyester plasticizer $^{12}$, epoxidized cardanol diethyl phosphate ${ }^{13}$, glucose esters ${ }^{14}$, citric acid ester ${ }^{15}$, phosphaphenanthrene groups-containing soybean-oil-based plasticizer ${ }^{16}$, soybean oil based polyol ester plasticizers ${ }^{17}$ and so on. However, all of these plasticizers are external plasticizer and easily leach from poly(vinyl chloride)(PVC) materials with increasing of time. The internal plasticizer is a part of polymer matrix and covalently bond to the chemical structure, which can resolve the leaching problem. Recently, Braslau et al. and Yang et al. reported the strategy for plasticization of PVC via click reaction. The obtained PVC materials presented lower transition temperature comparable with that of the conventional plasticized $\mathrm{PVC}^{18-20}$. In addition, highly self-plasticized PVC via chemical reaction of hyperbrabched polyglycerol was also reported by Lee et al. ${ }^{21}$ Navarro et al. ${ }^{22}$ developed several synthetic strategies to substitute chlorine with TCTA-based sodium thiolates with different aliphatic chains. In the study, a monooctyl phthalate derivative was synthesized, which was covalently bonded to the chemical structure of azide-functionalized PVC as an internal plasticizer. Chemical structure of the modified PVC material (M-PVC) was characterized by FTIR and ${ }^{1} \mathrm{H}$ NMR. The plasticization effect was studied with DSC. The migration resistance of phthalates plasticizer in distilled water, $10 \%(\mathrm{v} / \mathrm{v})$ ethanol, $30 \%(\mathrm{w} / \mathrm{v})$ acetic acid and petroleum ether was studied.

\section{EXPERIMENTAL}

\section{Material}

Phthalic anhydride, octanol, chloroform, dioctyl phthalate (DOP), propargyl bromide solution, potassium carbonate, sodium azide, $N, N$-dimethylformamide (DMF), acetone, cuprous bromide, 5,5-dimethyl-2,2-dipyridyl were kindly provided by Nanjing Chemical Reagent Co., Ltd. All of the chemical reagents are Polyvinyl chloride (PVC) was supplied by Hanwha (KM-31, South Korea).

Synthesis of monooctyl phthalate was according on the reference $^{23}$

${ }^{1} \mathrm{H}$ NMR(300MHz, $\left.\mathrm{CDCl}_{3}\right): 10.39(\mathrm{~s})-\mathrm{COOH} ; 7.80(\mathrm{~s})$ $-\mathrm{CH}=\mathrm{CH}-\mathrm{COOH} ; 7.60(\mathrm{~s})-\mathrm{CH}=\mathrm{CH}-; 7.40(\mathrm{~s})-\mathrm{CH}=\mathrm{CH}-$ $-\mathrm{COOC}_{8} \mathrm{H}_{17} ; 4.13(\mathrm{~s})(\mathrm{O}=\mathrm{C})-\mathrm{CH}_{2}-; 3.55(\mathrm{~s})-\mathrm{OH} ; 1.67(\mathrm{~s})$ $-\mathrm{CH}-; 1.23(\mathrm{~s})-\left(\mathrm{CH}_{2}\right)_{\mathrm{n}}-; 0.84(\mathrm{~s})-\mathrm{CH}_{3}$.

FT-IR (KBr): 2958 (=C-H); 2928(- $\left.\mathrm{CH}_{2}-\right) ; 2859\left(-\mathrm{CH}_{3}\right)$; $1724(-(\mathrm{O}=\mathrm{C})-\mathrm{OH}) ; 1698(\mathrm{C}=\mathrm{O}) ; 1580(\mathrm{C}=\mathrm{C})$.

Monooctyl phthalate derivative was synthesized according to the following steps.

Monooctyl phthalate $(13.9 \mathrm{~g}, 50 \mathrm{mmol})$, propargyl bromide solution( $6.5 \mathrm{~g}, 55 \mathrm{mmol})$, and potassium carbonate (7.6 g, $55 \mathrm{mmol}$ ) was mixed in $100 \mathrm{~mL}$ of acetone and stirred at $65^{\circ} \mathrm{C}$ for $12 \mathrm{~h}$. The solution was washed with distilled water. Then the monooctyl phthalate derivative was gotten after purring by evaporating under vacuum.

${ }^{1} \mathrm{H} \mathrm{NMR}\left(300 \mathrm{MHz}, \mathrm{CDCl}_{3}\right): 7.56(\mathrm{~s})-\mathrm{CH}=\mathrm{CH}=-\mathrm{C}-$ $\mathrm{O} ; 7.34(\mathrm{~s})-\mathrm{CH}=\mathrm{CH}-; 4.80(\mathrm{~s})(\mathrm{O}=\mathrm{C})-\left(\mathrm{CH}_{2}\right)_{\mathrm{n}}-; 4.10(\mathrm{~s})$ 
$(\mathrm{O}=\mathrm{C})-\mathrm{CH}_{2}-\mathrm{C} \equiv \mathrm{CH} ; 2.55(\mathrm{~s})-\mathrm{C} \equiv \mathrm{CH} ; 1.58(\mathrm{~s})-\mathrm{CH}-$; $1.19(\mathrm{~s})-\left(\mathrm{CH}_{2}\right)_{\mathrm{n}}-; 0.75(\mathrm{~s})-\mathrm{CH}_{3}$.

FT-IR (KBr): 3272 ( $=\mathrm{C}-\mathrm{H}) ; 2958(=\mathrm{C}-\mathrm{H}) ; 2929\left(-\mathrm{CH}_{2}-\right)$; $2860\left(-\mathrm{CH}_{3}\right) ; 2321(-\mathrm{C} \equiv \mathrm{CH}) ; 1722(\mathrm{C}=\mathrm{O}) ; 1580(\mathrm{C}=\mathrm{C})$.

\section{Synthesis of $\mathbf{P V C}-\mathrm{N}_{3}$ was according to the reference ${ }^{21}$}

PVC- $\mathrm{N}_{3}$ was prepared by dissolving $2.00 \mathrm{~g}$ of PVC and $2.00 \mathrm{~g}$ of $\mathrm{NaN}_{3}$ in $100 \mathrm{~mL}$ of DMF. The solvent was allowed to stir at $30^{\circ} \mathrm{C}$ for $24 \mathrm{~h}$ and precipitated into water/methanol mixture ( $1 / 1$ by volume), and dried in a vacuum to obtain the PVC- $\mathrm{N}_{3}$.

${ }^{1} \mathrm{H} \operatorname{NMR}\left(300 \mathrm{MHz}, \mathrm{CDCl}_{3}\right): \delta{ }^{4} 4.20-4.50$ (br m, $1 \mathrm{H}$ Cl-C-H), 2.40-2.70(br m, $2 \mathrm{H} \mathrm{CH}_{2}$ ).

FT-IR (KBr):2908(aliphatic C-H stretch), 2108 $(\mathrm{N}=\mathrm{N}=\mathrm{N}$ stretch), 1426 (C-H aliphatic bending), 1252 (C-C aliphaticbending), 609(C-Cl stretch) $\mathrm{cm}^{-1}$.

Elemental analysis: $35.13 \% \mathrm{C}, 8.21 \% \mathrm{H}, 18.47 \% \mathrm{~N}$, and $38.19 \% \mathrm{Cl}$.

\section{Preparation of modified PVC material}

Modified PVC materials (M-PVC) was prepared by dissolving $2.00 \mathrm{~g}$ of PVC- $\mathrm{N}_{3}, 1.20 \mathrm{~g}$ of propargyl ether monooctyl phthalate derivative, $0.18 \mathrm{~g}$ of cuprous bromide, $0.44 \mathrm{~g}$ of 5,5-dimethyl-2,2-dipyridyl in $50 \mathrm{~mL}$ of DMF in a three-neck flask, which was installed with a mechanical stirrer, nitrogen pipe and thermometer. The reaction was kept at $30^{\circ} \mathrm{C}$ and stirred for $24 \mathrm{~h}$. Then the mixture was precipitated into water/methanol mixture (1/1 by volume) after filtering to remove the copper salts, and dried in a vacuum to get the modified PVC materials. Figure 1 showed the synthesis of M-PVC.

\section{Characterization}

FT-IR spectra of PVC, PVC-N ${ }_{3}$ and M-PVC were detected on a Nicolet iS10 FTIR measurement (Nicolet Instrument Crop., USA). The spectra were acquired in the range of $4000 \mathrm{~cm}^{-1}$ to $500 \mathrm{~cm}^{-1}$ at a resolution of $4 \mathrm{~cm}^{-1}$.

${ }^{1} \mathrm{H}$ NMR measurements were conducted on an AV-300 NMR spectrometer (Bruker Instrument Crop., Germany) at a frequency of $400 \mathrm{MHz}$. $\mathrm{CDCl}_{3}$ was used as solvent and tetrametnylsilane (TMS) as an internal standard.

Elemental analysis was conducted on an elemental PE-2400 analyzer (PERKINELMER Instrument Crop., USA).

Thermogravimetric analysis (TGA) was investigated using a TG209F1 TGA thermal analysis instrument (Netzsch Instrument Crop., Germany) in $\mathrm{N}_{2}$ atmosphe- re $(50 \mathrm{~mL} / \mathrm{min})$ at a heating rate of $10^{\circ} \mathrm{C} / \mathrm{min} .5 \mathrm{mg}$ of samples were put into platinum pans and scanned from $40^{\circ} \mathrm{C}$ to $500^{\circ} \mathrm{C}$.

Glass transition temperature (Tg) of PVC materials was characterized using a NETZSCH DSC 200 PC analyzer. The temperature was heated up from $-20^{\circ} \mathrm{C}$ to $120^{\circ} \mathrm{C}$ and quenched. The DSC data was collected from the first cycle of heating to wipe out the previous thermal history of the sample before the actual measurement.

Migration of plasticizer was tested in according to ASTMD1239-98. The tested temperature was at $25^{\circ} \mathrm{C}$. The relative humidity was $50 \%$. The PVC materials after weighting were placed in distilled water, $10 \%(\mathrm{v} / \mathrm{v})$ ethanol, $30 \%(w / v)$ acetic acid and petroleum ether, respectively. After $24 \mathrm{~h}$, the solvent extracted PVC products were dried and reweighed. The extraction loss was calculated according to the Equation 1. Equation 1: Degree of migration $\left.=\left[\left(W_{1}-W_{2}\right) / W_{1}\right)\right] \times 100$, where $W_{1}=$ initial weight of test specimen, and $W_{2}=$ final weight of test PVC specimen.

\section{RESULTS AND DISCUSSION}

Chemical composition and structure of M-PVC were characterized by elemental analysis, FT-IR and ${ }^{1} \mathrm{H}$ NMR. The elemental analysis presented that chemical composition of M-PVC was $43.21 \% \mathrm{C}, 10.69 \% \mathrm{H}, 13.6 \% \mathrm{~N}$, $31.7 \% \mathrm{Cl}$ and $1.8 \% \mathrm{O}$. As seen from Figure 2(1), the characteristic absorption peak of $-\mathrm{N}_{3}$ band for azide-functionalized PVC appeared at $2108 \mathrm{~cm}^{-1}$, which presented weaker than that of PVC- $\mathrm{N}_{3}$. The absorption peak at $1728 \mathrm{~cm}^{-1}$ appeared stronger corresponding to ester band of monooctyl phthalate derivative, the results illustrated that monooctyl phthalate derivative reacted with $\mathrm{PVC}-\mathrm{N}_{3}$. To further investigate the chemical structure of M-PVC, ${ }^{1} \mathrm{H}$ NMR spectra of M-PVC was also detected. As shown in Figure 2(2), the protons of benzene ring were found at $\delta 7.55 \mathrm{ppm}$ and $\delta 7.71 \mathrm{ppm}$ (peak e). The strong peak at $\delta 7.28 \mathrm{ppm}$ attributed the $\mathrm{CDCl}_{3}$ solvent. The peaks at around $\delta 4.22-4.61 \mathrm{ppm}($ peak $\mathrm{a}+\mathrm{b})$ attributed to protons of N-CH- $\left(\mathrm{CH}_{2}\right)$ - and $\mathrm{Cl}-\mathrm{CH}-\left(\mathrm{CH}_{2}\right)$. The peaks at $\delta 2.07$ and $\delta 2.03 \mathrm{ppm}$ (peak $\mathrm{c}+\mathrm{d}$ ) attributed to the protons of $\mathrm{Cl}-\mathrm{CH}-\left(\mathrm{CH}_{2}\right)$. The peaks at $\delta 0.92$ (peak f), 1.26 (peak g) and $1.65 \mathrm{ppm}$ (peak h) were corresponded the protons of methyl and methylene, respectively. All of theses dates indicated that the monooctyl phthalate derivative was reacted with PVC- $\mathrm{N}_{3}$.
(1)

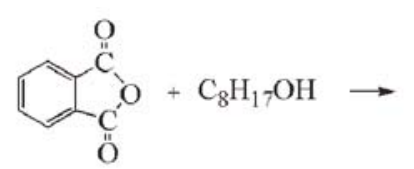<smiles>CCOC(=O)c1ccccc1C(=O)O</smiles><smiles></smiles><smiles>C=CCOC(=O)c1ccccc1OC(=O)OCC</smiles>

Phthalic anhydride Octanol Monooctyl phthalate
Propargyl ether monooctyl phthalate

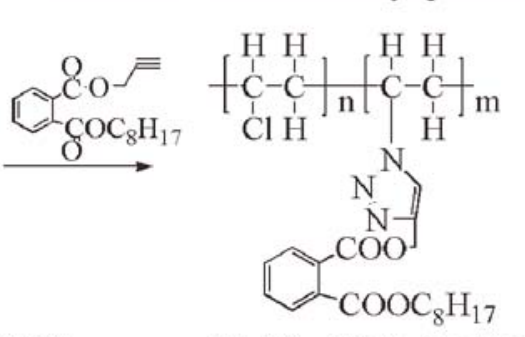




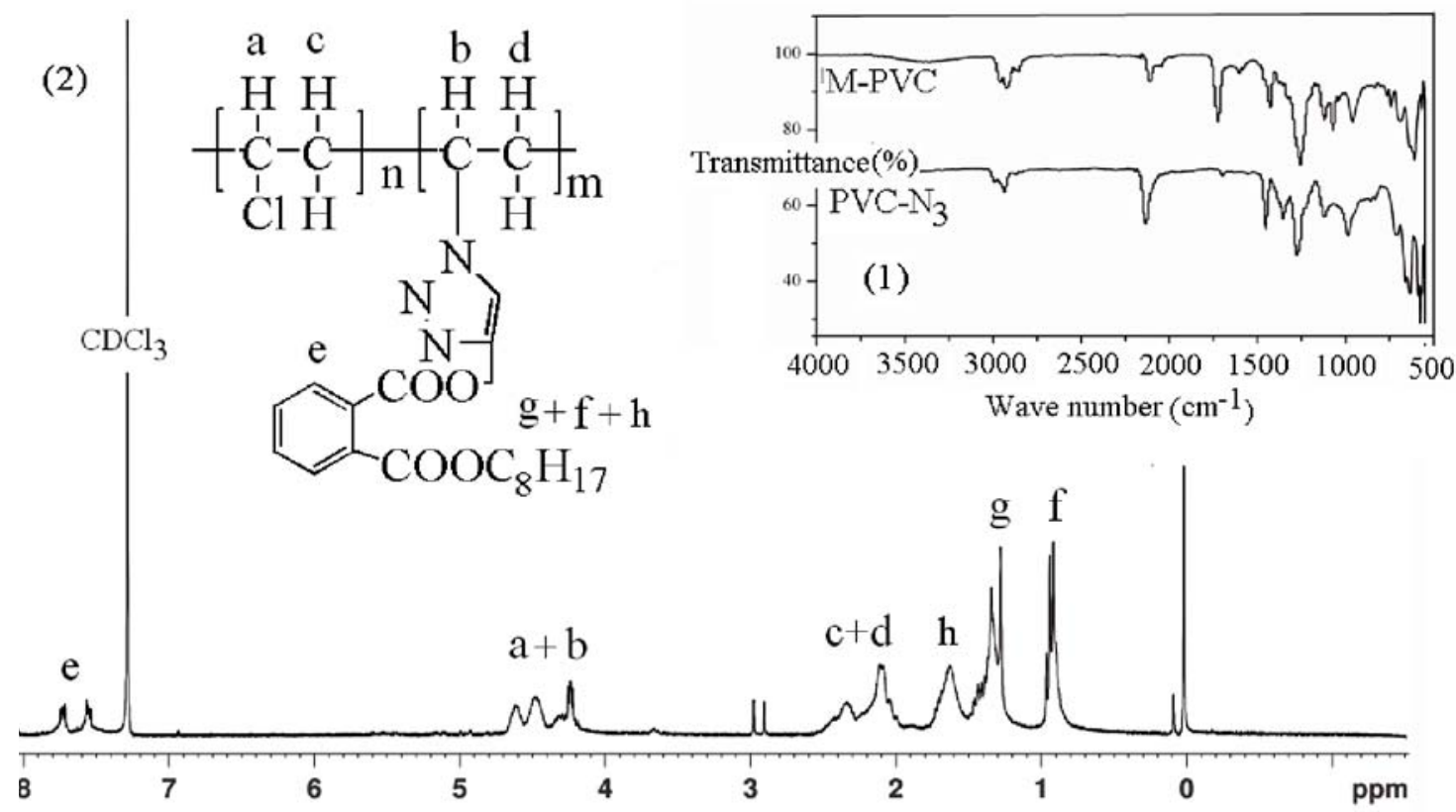

Figure 2. (1) FT-IR spectra of M-PVC and PVC-N3; (2) 1H NMR spectrum of M-PVC

TGA and DSC were used to investigate the thermal properties of PVC and M-PVC. As shown in Figure 3 (A), PVC materials began to degrade at above $170^{\circ} \mathrm{C}$. Apparently, the thermal stability of PVC was better than that of M-PVC, because thermal degradation process of PVC lagged behind M-PVC during the whole thermal degradation process. The whole thermal degradation of synthesized PVC material presented two stages.
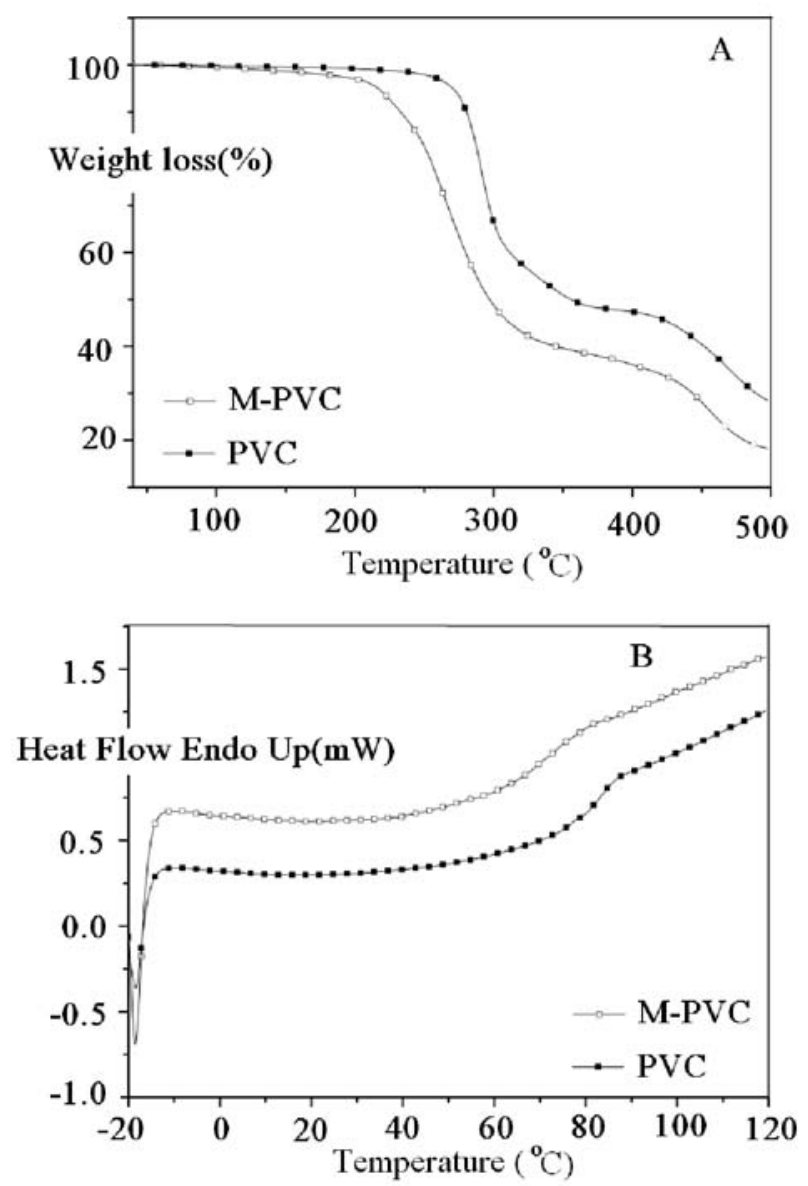

Figure 3. (A) TGA curves of PVC and M-PVC; (B) DSC curves of PVC and M-PVC
Dehydrochlorination of PVC occurred at 250-350. Cyclization of conjugated polyene sequences forming aromatic compounds occurred in the temperature range of $350-500^{\circ} \mathrm{C}$. The covalent bonding of azide group on PVC chains made the material easily degradable. DSC curves of PVC and M-PVC were shown in Figure 3 (B), a change in heat capacity approximately at $78.1^{\circ} \mathrm{C}$ was shown in DSC curves of PVC, which was attributed to the Tg of PVC. A slight decrease of $\mathrm{Tg}$ of $66.0^{\circ} \mathrm{C}$ was observed in the DSC curves of M-PVC. The results showed that the internal plasticizer increased the distance between PVC chains and decreased intermolecular force of M-PVC chains, which further increased segment mobility of M-PVC chains, and decreased the Tg of PVC efficiently. Tg of the modified PVC was lower than that of the unmodified PVC indicated that the plasticization effect was successful. The migration degree of plasticizer was presented in our previous study ${ }^{10}$. The migration degree of DOP migrated out from the PVC blends (40\% wt of DOP) in was 1.4\%, 1.55\%, 3.45\%, $2.01 \%$ in distilled water, $10 \%(\mathrm{v} / \mathrm{v})$ ethanol, $30(\mathrm{w} / \mathrm{v})$ acetic acid and petroleum ether, respectively ${ }^{5}$, but no migration was observed for M-PVC. The results indicated that the use of internal plasticizer avoided migration, which can maintain properties of the PVC products for long stable, and decrease the possible threat of toxic to human body. The M-PVC material can be used in the area with high requirement in migration stability.

\section{CONCLUSIONS}

In the study, a kind of PVC material with suppressed migration was prepared via click reaction of a monooctyl phthalate derivative. FT-IR, ${ }^{1} \mathrm{H}$ NMR and element analysis were used to investigate the chemical structure and composition of M-PVC. TGA and DSC showed that M-PVC exhibited poor thermal stability, and a low glass transition temperature $(\mathrm{Tg})$ of $66.0^{\circ} \mathrm{C}$. Migration tests showed that no migration was found in distilled water, $10 \%(\mathrm{v} / \mathrm{v})$ ethanol, $30 \%$ (w/v)acetic acid and petroleum ether. The PVC material can be used prepared 
PVC products in areas with high migration resistance requirement. The method provided general method for preparing PVC materials without migration.

\section{ACKNOWLEDGEMENTS}

This work was supported by the Fundamental Research Funds from Jiangsu Province Biomass and Materials Laboratory (JSBEM-S-2017010); the President of the Chinese Academy of Forestry Foundation (CAFYB-B2014QB021).

\section{LITERATURE CITED}

1. Jia, P., Zhang, M., Hu, L., Feng, G. \& Zhou, Y. (2015). Synthesis of novel caged phosphate esters and their flame retardant effect on poly(vinyl chloride) blends. Chem. Lett. 44, 1220-1222. DOI: 10.1246/cl.150374.

2. Silva, M.A.D., Vieira, M.G.A., Maçumoto, A.C.G. \& Beppu, M.M. (2011). Polyvinylchloride (PVC) and natural rubber films plasticized with a natural polymeric plasticizer obtained through polyesterification of rice fatty acid. Polym. Test. 30, 478-484. DOI: http://dx.doi.org/10.1016/j.polymertesting.2011.03.008.

3. Saeki, Y. \& Emura, T. (2002). Technical progresses for PVC production. Prog. Polym. Sci. 27, 2055-2131. DOI: http:// dx.doi.org/10.1016/S0079-6700(02)00039-4.

4. Bocqué, M., Voirin, C., Lapinte, V., Caillol, S. \& Robin. J.J. (2016). Petro-based and bio-based plasticizers: Chemical structures to plasticizing properties. J. Polym. Sci. Part A: Polym. Chem. 54(1), n/a-n/a. DOI: 10.1002/pola.27917.

5 Jia, P., Zhang, M., Hu, L., Feng, G., Bo, C. \& Zhou. Y. (2015). Synthesis and application of environmental castor oil based polyol ester plasticizers for poly(vinyl chloride). ACS Sustainable Chem. Eng. 3(9), 2187-2193. DOI:10.1021/acssuschemeng.5b00449.

6. Lindstrom, A. \& Hakkarainen. M. (2007). Migration resistant polymeric plasticizer for poly(vinyl chloride). J. Appl. Polym. Sci. 104, 2458-2467. DOI: 10.1002/app.24777.

7. Latini, G., De, F.C. \& Verrotti, A. (2004). Plasticizers, infant nutrition and reproductive health. Reprod. Toxicol. 19, 27-33. DOI: 10.1016/j.reprotox.2004.05.011.

8. Coltro, L., Pitta, J.B. \& Madaleno. E. (2013). Performance evaluation of new plasticizers for stretch PVC films. Polym. Test. 2(2), 272-278. DOI: http://dx.doi.org/10.1016/j. polymertesting.2012.11.009.

9. Yu, B.Y., Chung, J.W. \& Kwak. S.Y. (2008). Reduced migration from flexible poly(vinyl chloride) of a plasticizer containing beta-cyclodextrin derivative. Environ. Sci. Technol. 42(19), 7522-7527. DOI: 10.1021/es800895x.

10. Jia, P.Y., Zhang, M., Liu, C., Hu, L., Feng, G., Bo, C. \& Zhou, Y. (2015). Effect of chlorinated phosphate ester based on castor oil on thermal degradation of poly (vinyl chloride) blends and its flame retardant mechanism as secondary plasticizer. RSC Adv. 5, 41169-41178. DOI: 10.1039/C5RA05784A.

11. Bueno-Ferrer, C., Garrigós, M.C. \& Jiménez, A. (2010). Characterization and thermal stability of poly(vinyl chloride) plasticized with epoxidized soybean oil for food packaging. Polym. Degrad. Stab. 95, 2207-2212. DOI: 10.1016/j.polymdegradstab.2010.01.027.

12. Jia, P., Zhang, M., Hu, L. \& Zhou, Y. (2016). A novel biobased polyester plasticizer prepared from palm oil and its plasticizing effect on poly (vinyl chloride). Pol. J. Chem. Technol. 18(1), 9-14. DOI: 10.1515/pjct-2016-0002.

13. Prabhakaran, K., Narayanan, A. \& Pavithran, C. (2001). Cardanol as a dispersant plasticizer for an alumina/toluene tape casting slip. J. Eur. Cream Soc. 21, 2873-2878. DOI: http:// dx.doi.org/10.1016/S0955-2219(01)00228-X.
14. Yang, X. \& Hakkarainen, M. (2015). Migration resistant glucose esters as bioplasticizers for polylactide. J. Appl. Polym. Sci. 132(18). DOI: 10.1002/app.41928.

15. Schilling, S.U., Shah, N.H., Malick, A.W., Infeld, M.H. \& McGinity, J.W. (2007). Citric acid as a solid-state plasticizer for Eudragit RS PO. J. Pharm. Pharmacol. 59, 1493-1500. DOI: 10.1211/jpp.59.11.0005.

16. Jia, P., Zhang, M., Hu, L., Feng, G., Bo, C., Liu, C. \& Zhou, Y. (2015). Synthesis and application of phosphaphenanthrene groups-containing soybean-oil-based plasticizer. Ind. Crop. Prod. 76, 590-603. DOI: http://dx.doi.org/10.1016/j. indcrop.2015.07.034.

17. Jia, P., Zhang, M., Hu, L., Feng, G., Bo, C., Liu, C. \& Zhou, Y. (2016). Green plasticizers derived from soybean oil for poly(vinyl chloride) as a renewable resource material. Korean J. Chem. Eng. 33(3), 1-8. DOI: 10.1007/s11814-015-0213-9.

18. Earla, A. \& Braslau, R. (2014). Covalently Linked Plasticizers: Triazole Analogues of Phthalate Plasticizers Prepared by Mild Copper-Free "Click" Reactions with Azide-Functionalized PVC. Macromol. Rapid. Comm. 35, 666-671. DOI: 10.1002/ marc. 201300865.

19. Earla, A., Li, L., Costanzo, P. \& Braslau, R. (2016). Phthalate plasticizers covalently linked to PVC via copper-free or copper catalyzed azide-alkyne cycloadditions. Polymer. DOI: 10.1016/j.polymer.2016.12.014

20. Yang, P., Yan, J., Sun, H., Fan, H., Chen, Y., Wang, F. \& Shi, B. (2015). Novel environmentally sustainable cardanol-based plasticizer covalently bound to PVC via click chemistry: synthesis and properties. Rsc. Adv. 5, 16980-16985. DOI: 10.1039/C4RA15527K.

21. Lee, K.W., Chung, J.W. \& Kwak, S. (2016). Structurally enhanced self-plasticization of poly(vinyl chloride) via click grafting of hyperbranched polyglycerol. Macromol. Rapid. Comm. DOI: 10.1002/marc.201600533.

22. Navarro, R., Perrino, M.P., García, C., Elvira, C., Gallardo, A. \& Reinecke, H. (2016) Highly Flexible PVC Materials without Plasticizer Migration As Obtained by Efficient One-Pot Procedure Using Trichlorotriazine Chemistry. Macromolecules DOI: 10.1021/acs.macromol.6b00214.

23. Hu, Z. \& Di, C. (2003). Preparation of mono-2-ethlhexyl maleate and mono-2-ethylo-phthalate. Jiangsu Chem. Ind. 31, 38-39. 